\title{
Adolescent Involvement at Public Horticulture Institutions
}

\author{
Keelin Blaith Purcell ${ }^{1}$, Robert E. Lyons ${ }^{1,4,5}$, Lynn D. Dierking ${ }^{2}$, \\ and Helen Fischel ${ }^{3}$
}

ADDITIONAL INDEX WORDs. youth programming, education, teenage, public garden

SUMMARY. While public gardens typically offer educational programming for adults and elementary school-aged children, many institutions struggle with serving the teenage audience. This study gathered information on the institutional benefits, challenges, and strategies of offering successful programming for youth aged 13-19 years. Institutional members of the American Public Gardens Association were surveyed, followed by case study research at two large institutions and phone interviews with three smaller institutions. Seven institutional benefits emerged, the three foremost being building relationships with new audiences, building interest in horticulture, and supporting the institution's mission and growth. In addition, seven potential challenges were identified, most notably funding, staff time, and adolescent interest. Seven overarching strategies also emerged, highlighting the areas of high quality staff, curriculum, partnerships, youth decision-making, compensation, engaging activities, and evaluation.

$\mathrm{O}$ ne role of public horticulture institutions, and museums in general, is the education of their visitors and their community. While many gardens offer educational programming for adults and elementary school-aged children, the teenage audience seems to be largely underserved. Stereotypes of both teenagers and museums can make museums hesitant to engage teenagers and teenagers hesitant to come to museums (Beane, 2000). However, stereotypes should not be a barrier to new programming, and public gardens and adolescents can be productive partners. Engaging teenagers can help to develop new audiences, enhance future visitation, and cultivate potential donors and, using the unique youth perspective, can greatly contribute to the variety and effectiveness of programming [Association of Science-Technology Centers (ASTC), 2001; Batcke, 2007]. There is a wealth of literature addressing adolescent development and successful programming in museums and

This paper is a portion of a Master's thesis submitted by Keelin Blaith Purcell in fulfilling a degree requirement.

${ }^{1}$ Longwood Graduate Program, University of Delaware, 125 Townsend Hall, Newark, DE 19716

${ }^{2}$ Sea Grant Professor in Free-Choice Learning, Department of Science and Mathematics Education, Oregon State University, 235 Weniger Hall, Corvallis, OR 97331

${ }^{3}$ Associate Director of Education, Delaware Nature Society, P.O. Box 700, Hockessin, DE 19707

${ }^{4}$ Professor and Director.

${ }^{5}$ Corresponding author. E-mail: rlyons@udel.edu. other cultural institutions, which offers guidance and suggests specific program strategies. The big question is whether public horticulture institutions are capitalizing on this research to play a major role in the lives of today's adolescents.

Teenagers are ready and willing to be involved with cultural institutions. In fact, many teenagers need these types of experiences to develop into healthy and productive adults (Bell et al., 2009; Eccles and Gootman, 2002). More studies indicate that teenagers are not prepared for college or for the workplace and that traditional education does not build certain life skills, such as communication and leadership (Casner-Lotto and Barrington, 2006; Catalano et al., 2004; Eccles and Gootman, 2002; Mancini and Marek, 1998). Well-designed after-school programs can be extremely beneficial for adolescent development (Beane, 2000; Bowles and Brand, 2009; Carnegie Corporation of New York, 1995; Catalano et al., 2004; McLaughlin, 2000; Quinn, 1999). Teenagers are looking for opportunities to interact with peers and adults in fun settings, to be empowered, and to gain new skills for their future (Sturman, 2006).

At the same time, enrollment in plant science and horticulture curricula is declining (Darnell and Cheek, 2005 ; R.E. Lyons, personal communication). Children are spending less time outdoors interacting with nature, leaving some wondering who will be the next generation of naturalists and environmentalists (Louv, 2005). Given that youth programs at museums have been proven to build specific knowledge and skills related to the institution (Koke and Dierking, 2007, 2010) and to support adolescent development through the very opportunities previously described, the potential impact for effective adolescent programming at public horticulture institutions is enormous. Public gardens can partner with the community to both support youth development and actively engage youth in horticulture and environmental issues. Providing real-life and longterm horticultural experiences during these formative years could help ensure an active and engaged future generation of horticulturists and public garden and environmental advocates.

The objective of this research was to determine what specific institutional benefits could be derived from offering long-term adolescent programming and to articulate potential challenges and specific strategies of running successful programs. The following research questions guided this research: 1) What is the current state of adolescent programming at public horticulture institutions? In what ways is the public garden community serving the adolescent audience? 2) What are the perceived and observed institutional benefits to offering long-term adolescent programming? 3) What are the perceived and observed institutional barriers to offering long-term adolescent programming? 4) How are successful long-term adolescent programs using and supporting different strategies?

The ultimate goal was to share research findings with public horticulture institutions to aid and inspire them to create and implement positive development opportunities for teenagers and to assume a greater role in the cultural and horticultural education of today's adolescents. For the purposes of this study, the terms "teenager," "youth," and "adolescent" were used interchangeably and refer to children aged 13-19 years. "Long-term" programming was defined as programming lasting a total of $7 \mathrm{~d}$ or more.

\section{Materials and methods}

Study Design. Data were collected using a sequential mixed methods approach. An in-depth questionnaire was developed and a pre-survey letter 
was mailed to all contacts 1 week before sending the questionnaire via e-mail. Two e-mail reminders were sent during the 3 weeks the survey was open. This survey was conducted in Apr. and May 2009. Based on survey findings, a follow-up survey was sent in Nov. 2009 to the directors of institutions who indicated they were offering long-term adolescent programming.

Additional data were gathered through case studies at two large institutions, as defined by the American Public Gardens Association (APGA), engaged in long-term youth programming: Chicago Botanic Garden and Brooklyn Botanic Garden. Phone interviews were also conducted at APGAdesignated small- and medium-sized institutions to gain further understanding about the opportunities and challenges of offering adolescent programming from the perspectives of institutions of that size. The institutions included in this aspect of the study were the Delaware Center for Horticulture, Bowman's Hill Wildflower Preserve, and Fellows Riverside Garden. Case study and phone interview data were collected in Aug. and Sept. 2009.

SAmple. As the primary professional organization for public horticulture institutions, APGA institutional members were chosen as the sample for this study. The APGA Executive Director provided a list of institutional member contacts, as well as any individual member who had "education" as part of their work title in case any designated institutional member contacts were not sufficiently familiar with adolescent programming at their institution. The researcher cross-referenced these lists and, where applicable, replaced designated institutional contacts with a more appropriate education department contact.

QuestionnaIre PROTOCOL. The survey consisted of 40 questions (Purcell, 2010) and was developed with built-in logic to gather information from different subsets of research participants and to streamline any one individual's response time. Portions of the survey instrument were modified from an online survey developed by the Institute for Learning Innovation for the Institute of Museum and Library Services (IMLS) "Museums and $\mathrm{Li}^{-}$ braries Engaging America's Youth Initiative" in 2006 (Koke and Dierking, 2007). The Institute for Learning Innovation and IMLS gave permission to use portions of this survey and to modify it as needed.

Questions were asked in all the research areas. Those addressing institutional benefits were open-ended. Seven potential challenges to offering youth programming were identified from past research and provided as such in the questionnaire, along with an "other" category. Based on the framework established by the IMLS study (Koke and Dierking, 2007), 11 strategies for running successful programming within the categories of capacity building, partnerships, youthdriven programming, and opportunities to contribute were probed. In addition, research participants were asked how often they conducted assessment and whether they felt their institution's programs fostered the "Six Cs" of positive youth development: competence, confidence, connections, character, caring, and contribution (Lerner, 2007). There was also an open-ended question about strategies for running successful programming.

CASE STUDY AND PHONE INTERVIEW PROTOCOL. Site visits at the two large institutions included observations, staff interviews, and the collection of materials related to programming, including application and evaluation forms, mission statements, and promotional materials. Data from these site visits were used to develop case studies of the two institutions and their programming to enable public horticulture professionals to understand the nuances and complexities of offering such programming. Phone interviews at medium- and smallsized institutions consisted of an interview with the most relevant staff. Program materials were gathered when available. All staff interviews were guided by a list of primarily open-ended questions (Purcell, 2010).

Data ANALysis. Survey data were compiled, entered, and analyzed using basic descriptive statistics. Case study interviews and phone interviews were digitally recorded and transcribed, and recurring themes were identified in both these data sets. Themes were extracted from the open-ended survey questions by analyzing all data and pinpointing themes that were mentioned consistently.

\section{Results}

The APGA institutional membership survey was sent to 481 contacts and completed by 190 individuals, resulting in a response rate of $39.5 \%$. This falls above the average response rate for online surveys, which has been estimated at $30 \%$ (University of Texas, 2007). The majority identified their institution as a botanic garden (50.8\%), a display garden $(32.6 \%)$, or an arboretum $(31.0 \%)$. The majority of the institutions were urban (45.7\%) and small (48.7\%) (Purcell, 2010).

The follow-up survey to directors of institutions offering long-term adolescent programming was sent to 53 contacts and completed by 32 , resulting in a response rate of $60.4 \%$. The results were grouped into the four main categories reflected in the research questions: current state of adolescent programming, institutional benefits, potential challenges, and strategies.

CuRRENT STATE of ADOLESCENT PROGRAMMING. Survey findings revealed that $65.8 \%$ of institutions offer adolescent programming, though only $28.9 \%$ offer long-term programming (Fig. 1). When research participants were asked what percentages of their

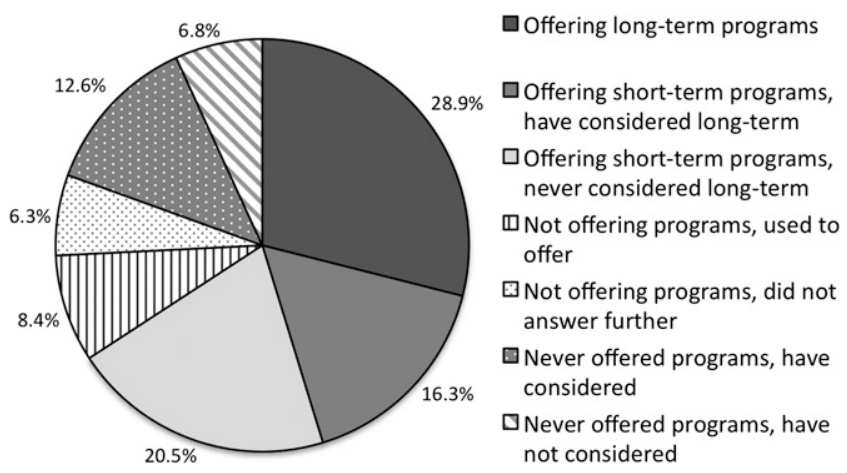

Fig. 1. Overall percentages of American Public Gardens Association institutional member survey participants offering or not offering adolescent programming at public horticulture institutions $(n=190)$. 
educational programs were designed for specific audiences, the answers indicated that those designed for adolescents had the lowest average at $8.9 \%$ (Fig. 2). When institutions offering long-term adolescent programming were asked about program success, $69.8 \%$ of participants indicated that their programs were overall successful (Fig. 3).

InSTITUTIONAL BENEFITS. Seven primary institutional benefits for offering long-term adolescent programming emerged from the surveys, case studies, and phone interviews. They were subsequently grouped into major and minor themes (Table 1 ).

Potential challenges. All important challenges fell within the seven challenges previously identified in the literature. These were grouped into major and minor themes (Table 2).

Strategies. Survey participants reported that they were using all the strategies provided in the questionnaire to a great extent for running successful programming. The wide range of strategies provided in answers to the questionnaire made the coding and analysis of the answers to open-ended questions about strategies difficult. Therefore, the results were compared with the literature to create a concise set of seven strategies for running successful programming (Table 3 ).

\section{Discussion \\ Current state of adolescent programming}

As there is a scarcity of empirical data about the current state of adolescent programming at public horticulture institutions, the results of this research give needed insight and direction in this area. The evidence creates shared knowledge of current offerings and highlights gaps in serving the adolescent audience. This information should be invaluable as institutions think critically about their own program offerings for adolescents.

One key result of this study is that the adolescent audience, on average, is served less than any other audience (Fig. 2), indicating a potential opportunity for program expansion. While a majority $(65.8 \%)$ of the institutions participating in the study do offer some type of adolescent programming, only $28.9 \%$ are offering long-term programming (Fig. 1), even though research suggests that these programs can have

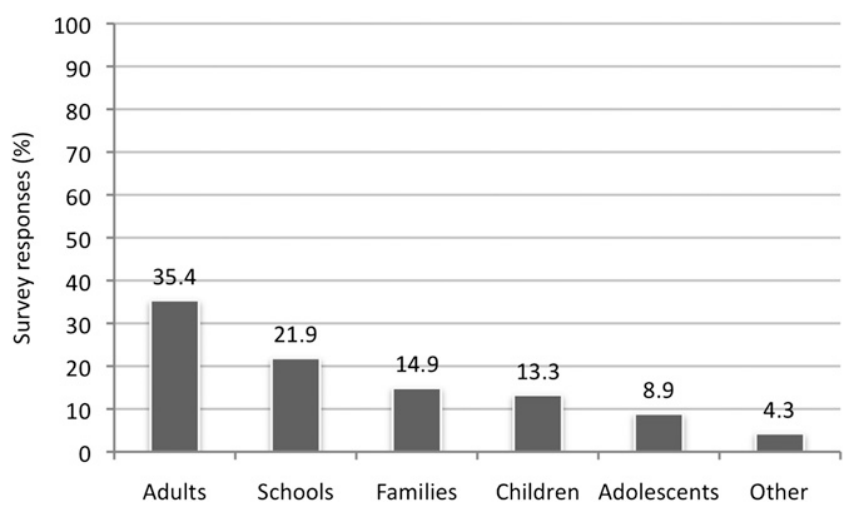

Fig. 2. Average percentages of educational programs designed for specific audiences at public horticulture institutions as reported in a survey of institutional members of the American Public Gardens Association $(n=125)$.

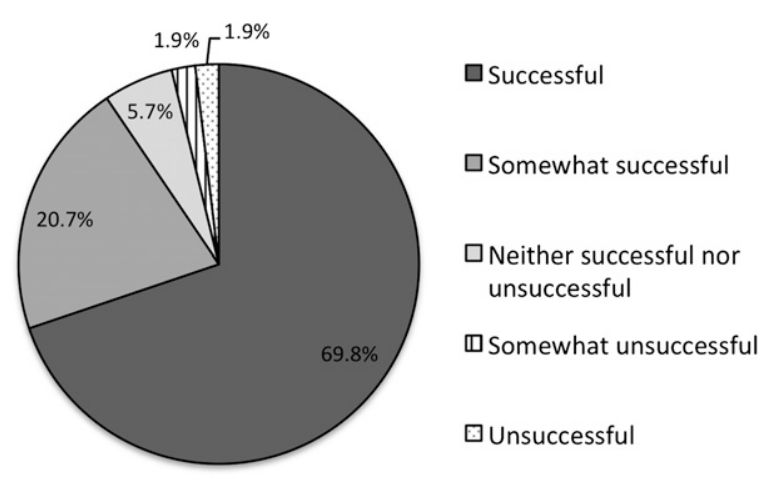

Fig. 3. Degree of overall success offering long-term adolescent programming at public horticulture institutions as reported in a survey of institutional members of the American Public Gardens Association $(\mathbf{n}=\mathbf{5 3})$.

Table 1. Major and minor institutional benefits of offering long-term $(>7 \mathrm{~d})$ adolescent programming at public horticulture institutions as identified through a survey, case studies, and phone interviews with American Public Gardens Association institutional members.

\begin{tabular}{ll}
\hline & \multicolumn{1}{c}{ Institutional benefits } \\
\hline Major & Builds relationships with new audiences who may be future employees \\
& or contributors \\
Builds interest in horticulture and environmental issues, including & career interests \\
& Supports the institution's mission and growth \\
Minor & Helps the institution contribute to and build the strength of the \\
& community \\
& Provides an inexpensive labor source \\
& Prings in new energy, ideas, and perspectives \\
\end{tabular}

a greater impact on the youth and the institution (Catalano et al., 2004; Downs, 2008; Koke and Dierking, 2007; McLaughlin, 2000; Schwartz, 2005). The potential opportunity for growth in this area is evidenced by the fact that $16.3 \%$ of institutions were not offering long-term programming but had considered it.
When asked about the success of long-term programming, $69.8 \%$ of institutions reported that they were overall successful (Fig. 3), with only $3.8 \%$ of institutions reporting that they were somewhat or totally unsuccessful. Although adolescent programming may seem challenging, this finding indicates that success is widely attainable. 


\section{Institutional benefits}

For institutions that are considering long-term adolescent programming, concrete institutional benefits are useful program justifications, especially when proposing the initiative to organizational leadership or other stakeholders. The major emergent benefits from this research of longterm youth programming included the following.

BUILDS RELATIONSHIPS WITH NEW AUDIENCES. This theme consistently emerged, and many institutions were enthusiastic about serving what is currently a gap in the audience spectrum. Many research participants wrote about engaging teenagers who could subsequently volunteer, bring their parents and siblings, become members, spread awareness of the institution, take classes, and become future interns, employees, or patrons, in the words of one survey participant, "building a larger, more loyal base of support." Past research demonstrates that teenagers who have meaningful experiences with an institution are likely to donate their time and money

Table 2. Major and minor potential challenges of offering long-term (>7 d) adolescent programming at public horticulture institutions as identified through a survey, case studies, and phone interviews with American Public Gardens Association institutional members.

\begin{tabular}{|c|c|}
\hline & $\begin{array}{l}\text { Potential } \\
\text { challenges }\end{array}$ \\
\hline Major & $\begin{array}{l}\text { Funding } \\
\text { Staff time } \\
\text { Adolescent interest }\end{array}$ \\
\hline Minor & $\begin{array}{l}\text { Expertise in working } \\
\text { with adolescents } \\
\text { Institutional support } \\
\text { Organizational leadership } \\
\text { Community support }\end{array}$ \\
\hline
\end{tabular}

as adults (Batcke, 2007). Interviewed staff mentioned that this benefit is not always about building relationships with new youth, but maintaining relationships with involved youth who have aged out of programs for children. One person commented: "If you don't serve the teenage audience, the kids that come to the garden when they are young are not going to see it as a place that they can continue to participate in and then they are off to college and good luck getting them back before they have their own children." Clearly, engaging teenagers at this formative age has the potential for long-term and substantial institutional benefits. In addition, engaging a diverse group of teenagers can help to build awareness among these youth of careers within the field of public horticulture and raise awareness about how to promote visitor diversity.

BUILDS INTEREST IN HORTICULTURE AND ENVIRONMENTAL ISSUES. Long-term programming can lead to increased knowledge of institutional content (Koke and Dierking, 2007; Wenger and Foutz, 2010), in this case meaning the skills and practices associated with a public garden. This is an especially important benefit to offering adolescent programming since this is the time when young people are beginning to make college and career choices. Learning experiences at this age can lead to self-efficacy, which is strongly related to career interests and choices (Tang et al., 2008). Many research participants spoke directly about fostering career interests, as evidenced by this representative response: "We want to develop an educated workforce of horticulturists and landscape/environmental stewards." Others spoke more broadly about the teenagers' environmental understanding, such as in the comment, "I think that it is important for them to connect with the natural world and to understand the relationship between people and plants as well as our environment." Although this may seem like an indirect institutional benefit, directors of institutions offering adolescent programming ranked this benefit as the most important and it consistently arose in open-ended questions. Building this interest early is very important to the future of public horticulture.

SUPPORTS THE INSTITUTION'S MISSION AND GROWTH. This is typically an inherent benefit of any programming and many research participants simply stated, unprompted, that adolescent programming fulfilled their mission. When asked directly, a majority of research participants said that adolescent programming would support their mission, or already does to a great extent. Some comments were more in-depth and addressed the opportunity that comes with long-term programming. For example, one research participant wrote that long-term programming provides "opportunities to explore the institutional mission from various approaches." Another mentioned the teenagers' "ability to work to fulfill the mission." These findings are supported by a report issued by the Innovation Center for Community and Youth Development (2001), which indicated, "most organizations found that young people help clarify and bring focus to the organization's mission." Therefore, institutions could see a direct benefit to their mission and growth, particularly when they think of youth, and especially underserved youth, as assets to the community rather than deficits.

\section{Potential challenges}

Identifying and understanding the challenges of offering adolescent

Table 3. Strategies for developing and offering long-term $(>7 \mathrm{~d})$ adolescent programming at public horticulture institutions as identified through a survey, case studies, and phone interviews with American Public Gardens Association institutional members.

\begin{tabular}{|c|c|}
\hline High quality staff & Hire experienced and high-quality program staff and ensure their continuity and stability. \\
\hline Curriculum & Establish a curriculum that builds life skills and competencies and provide access to key resources and staff. \\
\hline Partnerships & $\begin{array}{l}\text { Develop partnerships with local schools and community groups to assess community needs and } \\
\text { create awareness of your programming and its impact. }\end{array}$ \\
\hline Compensation & Provide adolescents with compensation and recognition for their contributions. \\
\hline Engaging activities & Provide a range of hands-on and engaging activities that build positive youth development characteristics. \\
\hline
\end{tabular}


programming is an important step in planning and addressing future programs. Although some challenges are unavoidable, some of the strategies uncovered in this study can help to address them. The major emergent challenges from this study are as follows.

Funding. Funding was consistently rated as a definite challenge and was the most frequent response when rated by institutions that were offering long-term programming and by directors of these institutions. This is supported by other studies discussing the high cost of running long-term adolescent programming (Grossman et al., 2009; Mancini and Marek, 1998) and the typical instability of funding from year to year (Quinn, 1999). Based on the researcher's observations, these realities may leave adolescent programming vulnerable during budget cuts and it is possible that the economic recession beginning in 2007 may have influenced these results, as many institutions are struggling financially. Although long-term adolescent programming is expensive, it can be an opportunity to bring in new funders who are particularly supportive of these types of programs, which was identified as a benefit in this study.

STAFF TIME. This was rated as the second most frequent challenge by institutions offering long-term programming and the directors of these institutions. To offer long-term programming that engages every participant and ultimately meets their needs, dedicated, trained, and knowledgeable employees are indispensable (McLaughlin, 2000). Staff interviewed at one of the case-study institutions spoke about the initial challenge of coming to terms with the number of staff needed to effectively conduct programming. In addition, one of the phone-interview institutions nearly had to stop offering adolescent programming because of the staff time involved. In particular, those interviewed felt that institutional support from the topdown is essential when it comes to dedicating adequate staff time.

Adolescent InTEREST. Although a majority of the institutions not offering adolescent programming were unsure if adolescent interest would be a large challenge, this concern did emerge as an actual challenge for institutions offering adolescent programming and directors of these institutions. In part, this referred to the recruitment of adolescents into a program. Recruitment depends upon not only promotion but also the developmental appropriateness of the program (Quinn, 1999) and its perception by peers, which is so critical at this stage of development. Peer-topeer promotion is particularly helpful at this age, and social media can be used in this process (ASTC, 2001).

In addition, "adolescent interest" referred to motivation and commitment to the program once the adolescent began participating. At case study and interview sites, the issue of continuing interest arose more often, especially with summer programs that had academic components and might have been perceived as too much like school by some youth. As identified in the institutional benefits results, being open to youth input on both the design and the evaluation of the program may help to address some of these challenges. In addition, paying teenagers a stipend can be motivating for youth who need to have an income, especially those from low-income communities (Wenger and Foutz, 2010).

\section{Strategies}

Because of the large number of strategies generated and often their specificity to an institution, it was difficult to draw conclusions from this research about which strategies work best. As indicated in the results, the case-study conversations about strategies were so diverse and specific that it was impossible to code them for themes. Fortunately, previous research has identified particular strategies and frameworks of successful youth development programming. These were used to create a concise list of seven strategies that may be useful in conceptualizing, planning, and evaluating adolescent programming at public horticulture institutions (Table 3), though, again, which strategies will be the most helpful is likely to be institution specific.

\section{Conclusion}

This research provides support and guidance for the discussion, planning, and review of long-term adolescent programming, whether an institution has ever contemplated these programs, is seriously considering initiating them, or has offered them for years. The analysis of adolescent programming in this study has also led to a better understanding of what public horticulture institutions are currently offering and can provide ideas for comparison and program initiation.

Understanding the major and minor institutional benefits can assist in initiating and promoting long-term adolescent programming. As the data demonstrates, such programming is not without its challenges, and an awareness of potential hurdles can help institutions assess those challenges in advance and plan strategically how to meet them. We also recommend using the identified institutional benefits and major challenges revealed in this study to assist in preparing for and beginning long-term adolescent programming. In addition to awareness of the benefits and challenges, strategies for successful youth development programming should also be considered and implemented.

This study demonstrates the potential for public horticulture institutions to make real and major differences in the lives of adolescents who live in their local community. In return, adolescent programming can help to grow the current and future audience of a garden, build interest in horticulture, and provide new inspiration and meaning to its organizational mission.

\section{Literature cited}

Association of Science-Technology Centers (ASTC). 2001. From enrichment to employment: The YouthALIVE! experience. ASTC, Washington, DC.

Batcke, A. 2007. Calling all teenagers. Cultural Qrtly. (Winter):8-9.

Beane, D.B. 2000. Museums and healthy adolescent development: What we are learning from research and practice. J. Mus. Educ. 25:3-8.

Bell, P., B. Lewenstein, A.W. Shouse, and M.A. Feder (eds.). 2009. Learning science in informal environments: People, places, and pursuits. Committee Learning Sci. Informal Environ., Natl. Res. Council, Washington, DC.

Bowles, A. and B. Brand. 2009. Learning around the clock: Benefits of expanded learning opportunities for older youth. Amer. Youth Policy Forum, Washington, DC.

Carnegie Corporation of New York. 1995. Great transitions: Preparing adolescents for a new century. Carnegie Corp. of New York, New York, NY. 
Casner-Lotto, J. and L. Barrington. 2006. Are they really ready to work? Employer's perspectives on the basic knowledge and applied skills of new entrants to the 21 st century U.S. workforce. Conf. Board/ Partnership 21st Century Skills/Corporate Voices Working Families/Soc. Human Resource Mgt., New York, NY.

Catalano, R.F., M.L. Berglund, J.A.M. Ryan, H.S. Lonczak, and J.D. Hawkins. 2004. Positive youth development in the United States: Research findings on evaluations of positive youth development programs. Ann. Am. Acad. Pol. Soc. Sci. 591:98-124.

Darnell, R.L. and J.G. Cheek. 2005. Plant science graduate students: Demographics, research areas, and recruitment issues. HortTechnology 15:677-681.

Downs, M. 2008. Nine to nineteen. Youth in museums and libraries: A practitioner's guide. Inst. Museum Library Services, Office Policy, Planning, Res. Commun., Washington, DC.

Eccles, J. and J.A. Gootman (eds.). 2002. Community programs to promote youth development. Natl. Acad. Press, Washington, DC.

Grossman, J.B., C. Lind, C. Hayes, J. McMaken, and A. Gersick. 2009. The cost of quality out-of-school-time programs. Public/Private Ventures/Finance Project, Philadelphia, PA.
Innovation Center for Community and Youth Development. 2001. At the table: Making the case for youth in decisionmaking. Innovation Ctr. Community Youth Dev./Natl. 4-H Council Univ. of Wisconsin-Madison/Natl. Assn. Ext. 4$\mathrm{H}$ Agents Youth in Governance Taskforce, Takoma Park, MD.

Koke, J. and L.D. Dierking. 2007. Museums and libraries engaging America's youth: Final report of a study of IMLS youth programs, 1998-2003. Inst. Museum Library Services, Washington, DC.

Koke, J. and L.D. Dierking. 2010. Engaging America's youth. ASTC Dimens. 2010 (Mar/Apr.):13.

Lerner, R.M. 2007. The good teen: Rescuing adolescence from the myths of the storm and stress years. Crown Publishing, New York, NY.

Louv, R. 2005. Last child in the woods: Saving our children from nature-deficit disorder. Algonquin Books, Chapel Hill, NC.

Mancini, J.A. and L.I. Marek. 1998. Patterns of project survival and organizational support: The national youth at risk program sustainability study. Virginia Coop. Ext. Serv. Publ. 350-800. 2 Nov. 2008. <http://www.ext.vt.edu/pubs/ family/350-800/350-800.html>.

McLaughlin, M.W. 2000. Community choice: How youth organizations matter for youth development. Public Educ. Network, Washington, DC.
Purcell, K.B. 2010. An analysis of adolescent involvement at public horticulture institutions. Univ. of Delaware, Newark, MS Thesis.

Quinn, J. 1999. Where need meets opportunity: Youth development programs for early teens. When School is Out 9:96116.

Schwartz, D.F. 2005. Dude, where's my museum? Inviting teens to transform museums. Museum News. 16 Nov. 2008. <http://www.aam-us.org/pubs/mn/ MN_SO05_teenagers.cfm $>$.

Sturman, T.D.M. 2006. Recommended practices for public gardens wishing to serve the teenage audience. Univ. of Delaware, Newark, MS Thesis.

Tang, M., W. Pan, and M.D. Newmeyer. 2008. Factors influencing high school students' career aspirations. Prof. Sch. Couns. 11:285-295.

University of Texas. 2007. Response rates. 10 Feb. 2010. <http://www. utexas.edu/academic/diia/assessment/ iar/teaching/gather/method/surveyResponse.php>.

Wenger, A. and S. Foutz. 2010. A journey with a CAUSE: Putting positive youth development into museum youth programs. ASTC Dimens. 2010(Mar):13. 